ÁLVARES, Lucas Parreira (...) USP - Ano X, n. 15, p. 135-146, 2019

\title{
Marx frente à sedução domesticável
}

Lucas Parreira Alvares

Doutorando em Antopologia pela Universidade Federal de Minas Gerais (UFMG)

\section{Resenha}

TIBLE, Jean. Marx indígena, preto, feminista, operário, camponês, cigano, palestino, trans. Selvagem. São Paulo: n-I Edições, 2019, 33p.

Palavras-chave Karl Marx, Marxismo, Identitarismo, Antropologia, Domesticação

Keywords Karl Marx, Marxism, Identirarism, Anthropology, Domestication 
$\mathrm{N}$ a nota do autor sobre a terceira edição do livro Marx Selvagem, Jean Tible afirma que optou "por fazer somente algumas mudanças, bem pontuais, de redação. Levar em conta todos os comentários, críticas e diálogos chama um novo livro, que deve vir, se tudo correr bem, logo" . Não temos a certeza se a publicação que aqui iremos resenhar, Marx indigena, preto, feminista, operário, camponês, cigano, palestino, trans. Selvagem, refere-se a esse novo livro anunciado por Tible. Tendemos a acreditar que não, exatamente pelas características que compóem esse pequeno texto em questão. De todo modo, o próprio autor afirma que essa nova publicação "retoma e prolonga argumentos do (...) livro Marx Selvagem, a partir de leituras e dos debates feitos desde o seu lançamento". Ou seja, mesmo que o texto aqui resenhado não seja esse "novo livro" prometido, ele pode ser compreendido como uma continuidade diante da sua matriz original que foi a tese de doutoramento de Jean Tible intitulada Marx e a América Indigena: diálogo a partir dos conceitos de abolição e recusa do Estado e publicada, com pequenas alterações, com o título Marx Selvagem.

Voltemos às especificidades que constituem nosso texto em questão: Marx indigena, preto, feminista, operário, camponês, cigano, palestino, trans. Selvagem. Trata-se de uma brochura enunciada como um "cordel” que compõe uma caixa desenvolvida pela editora n-I possuindo uma série de textos de outros autores como Eduardo Viveiros de Castro, Achille Mbembe, Antonio Negri, Carmem Silva, entre outros - com o intuito de financiar e sustentar a sua linha editorial. Sabemos que o mercado editorial nacional enfrenta dificuldades constantes e essa iniciativa da n-I constitui uma forma criativa de lidar com todos esses desafios. Segundo a própria editora, a série - cujo nome é "Pandemia" - não é apenas um "clube de assinatura de livros" nem mesmo um "financiamento coletivo". É mais do que isso: "ela serve para difundir ideias, pensamentos, instigar ações, mas também para ajudar a sustentar e a manter o projeto de longo prazo da n-I edições”, e conclui: "Quem se deixar contaminar por ela recebe uma série de benefícios, mas também contribui para que continuemos nosso trabalho, com a qualidade editorial de sempre". Por isso, a editora trata a série, em seus termos, como uma "guerrilha editorial" ${ }^{2}$. Acreditamos que a forma de publicação criada pela editora, bem como a qualidade do material específico de produção do autor, nos conduz à possibilidade de elaborar uma resenha crítica.

I TIBLE, Jean. Marx Selvagem. São Paulo: Autonomia Literária, 2018, p.9.

2 Para mais sobre a interessante série Pandemia, vide o link: https://n-Ipublications.org/assine-pandemia 
Feita essa breve introdução às especificidades do texto em questão, apresentaremos, por meio de três temáticas específicas, os principais argumentos de Marx indígena, preto, feminista, operário, camponês, cigano, palestino, trans. Selvagem que o expandem para além de sua matriz, o Marx Selvagem. em seguida, algumas interposições críticas serão necessárias; por fim, uma breve conclusão.

Os trabalhos de Jean Tible derivados de Marx Selvagem cumprem um papel aparentemente essencial: um convite para a retomada da leitura do próprio Marx. Apesar de considerarmos a proposta necessária, esse convite não se manifesta apenas como uma análise a partir de passagens do autor de $O$ Capital, mas sim, por meio de uma interpretação original que se desenvolve por meio de um diálogo de Tible com outros referenciais teóricos distintos daqueles que constituem a chamada "tradição marxista". Dividiremos nossa apresentação do texto a partir de alguns tópicos constitutivos do texto de Tible.

I) A primeira formulação de Tible que pretendemos apresentar é permeada pelas discussões contemporâneas da Antropologia, de alguns círculos filosóficos e de setores das ciências naturais que atestam para a suposta existência de uma nova era geológica. Segundo nosso autor, “o fim do capitalismo com 'rosto humano' se articula com outra questão fundamental: de 1750 até hoje, os direitos e liberdades modernos se expandiram na base do combustível fóssil. Nossas liberdades são intensivas em termos de energia” ${ }^{3}$. Desse modo, ao momento em que destruímos florestas e queimamos combustíveis fósseis, nos tornamos agentes geológicos, e assim, "fundamos o antropoceno, ou de forma mais precisa, o modo de produção tornou-se agente geológico: surge o capitaloceno”. Desse modo, prossegue Tible, "pensar com Marx hoje nos desafia a fazê-lo a partir desses múltiplos escombros, de ameaças à vida”. E assim, Tible nos convida a um exercício importante: o de aprender com conhecimentos indígenas, "conhecimento coletivo, situado e encarnado". E por fim, baseado em Donna Haraway, afirma novamente de maneira imperativa que "só uma perspectiva parcial nos permite uma visão objetiva, daí a importância de uma política localizada, posicionada" ${ }^{4}$.

2) A segunda formulação de Tible que queremos ressaltar é a que, de alguma forma, justifica o extenso título de seu cordel. Essa questão retoma uma das discussões mais sensíveis

3 Essa posição de Tible é baseada no argumento presente no seguinte texto: CHAKRABARTY, Dipesh. The climate of History: four theses”, Critical Inquiry, n.2, v.35, 2009.

4 HARAWAY, Donna. Saberes localizados: a questão da ciência para o feminismo e o privilégio da perspectiva parcial. Cadernos Pagu, n.5, 1995 . 


\section{R E VISTA A N G E L U N O V U S}

da tradição marxista, seja em seus termos clássicos ou mesmo em seu aparato contemporâneo. Segundo nosso autor, "Marx e o marxismo nomearam historicamente o sujeito revolucionário: tratava-se do operário industrial (e principalmente homem, branco, europeu ocidental)". Tible prossegue: "sem dúvida, o proletariado mostrou uma força de transformação extraordinária, mas também extremamente limitada, deixando muitas vezes de lado (ou ocultando) toda uma riqueza de lutas”. Desse modo, Tible afirma que Marx e o marxismo não levaram em conta "os elos entre capitalismo e patriarcado (...), entre capitalismo e escravidão, capitalismo e racismo". Continuando, nosso autor sugere que Marx e o marxismo também não levaram a sério "o fato de as resistências e alternativas ao capitalismo sempre envolverem múltiplos sujeitos: camponeses, mulheres, negros, bruxas, colonizados, indígenas, LGBTQIA e muitos outros”. Por fim, referenciado em Antonio Negri e Judith Butler, nosso autor afirma que "o marxismo tendeu sempre a se pautar por um universal (a classe) já dado. A este, podemos opor um comum, construído coletivamente por baixo, cuja base seria nossa vulnerabilidade e nossa precariedade comuns".

3) A terceira e última formulação que pretendemos apresentar é a hipótese central do autor que é retomada desde seu livro matriz: segundo Tible, existe um vínculo entre a teoria de Marx e o que o autor chama de "lutas". Assim, "a força e a especificidade de Marx e de seu pensamento vêm desse contato constante, sobretudo de sua capacidade de transformação por meio delas. Seus momentos de mudanças coincidem com a criatividade política de múltiplos atores”. Esse argumento é essencial para o entendimento da posição de Jean Tible como intérprete do pensamento de Marx. Isso fica ainda mais evidente quando o autor elenca o que entende como "lutas” e como Marx teria sido "contaminado” por elas. É necessário abrir as devidas aspas para o autor: "está presente nas mobilizações anticoloniais (na Irlanda, Índia, ou México), na comuna rural russa (na qual seu potencial comunista põe em xeque o evolucionismo) e na organização política iroquesa (e seu ímpeto libertário), que o desloca de certo eurocentrismo". Por mais que essas "lutas" de Tible dialoguem mais com as especificidades temáticas de seu texto, o autor também menciona "os impactos das revoluções de I848 e sua Primavera dos Povos, da Comuna de Paris de i871 e sua quebra do Estado, assim como dos seus sucessivos exílios”. E por fim, Tible conclui de maneira imperativa: "Marx deve ser visto a partir do seu pensamento-luta; não o trabalhar nessa perspectiva inviabiliza sua metodologia e seu caráter subversivo”.

Elencamos, portanto, algumas das principais contribuições de Tible em sua brochura Marx indigena, preto, feminista, operário, camponês, cigano, palestino, trans. Selvagem. A primeira delas diz respeito a uma centralidade da compreensão do tempo presente a partir de termos geológicos e socioambientais; quanto à segunda, Tible atesta uma suposta ausência de realização efetiva, por parte de Marx e do marxismo, em colocar em 
questão os chamados "múltiplos sujeitos" para se pensar o movimento por meio do qual há de superar o modo de produção capitalista; e por fim, a última e mais importante em sua exposição - no sentido de que constitui-se como uma hipótese que o autor teria identificado na extensão da obra de Marx - Tible sugere que o pensamento de Marx se modifica ao momento em que esse autor entra em contato com as "lutas" e, assim, Tible determina como imperativo e necessidade de pensarmos Marx sobre os termos de "pensamento-luta".

$\mathrm{O}$ que todas essas formulações têm em comum é a tentativa de reformular o pensamento de Karl Marx a partir de pressupostos externos a seu estatuto teórico. Nossa intenção, nesse momento, é de propor um exercício contrário: confrontar essas formulações frente às próprias determinações constitutivas do pensamento de Marx. A consequência imediata e inevitável de nosso trabalho é apresentar subsídios para o leitor validar ou questionar as formulações de Jean Tible.

Da mesma forma que enumeramos algumas das principais formulações de Tible em seu texto, nesse momento iremos enumerar nossas críticas conforme os assuntos previamente apresentados. Com isso pretendemos apresentar uma exposição sistematizada que implica em uma tentativa de elucidação das críticas postas sem recair em um esquematismo vulgar. Iniciemos, portanto, com a primeira formulação de Tible aqui apresentada.

I) Aceito por alguns estudiosos autodenominados marxistas, como o próprio Tible, a utilização do termo antropoceno deriva de sua popularização a partir das formulações do químico holandês Paul Crutzens para designar a humanidade como um determinante fator geológico na Terra a partir dos efeitos do aumento populacional e do desenvolvimento econômico no ambiente global, principalmente por meio da queima de combustíveis fósseis. Em última instância, tal formulação ao mesmo tempo em que culpabiliza a humanidade por meio de uma justificativa geológica dos danos ao "planeta", alia a densidade populacional a um genérico "desenvolvimento econômico", esse que, em seu uso, parece uma tentativa de não referenciar as questões reais em seus termos devidos. A consequência é que essa perspectiva deixa o capitalismo ileso enquanto um agente imediato da produção. Ora, quem, senão o grande capital extrativista são os responsáveis pelo uso abusivo de energias fósseis?

Já nos Grundrisse, Marx demonstrava que "na indústria extrativa (...) o trabalho consiste na simples superação dos obstáculos exigido para a captura e apropriação dos 


\section{R E V I S T A A N G E L S N O V U S}

produtos brutos ou produtos naturais", ou seja, "nenhuma matéria-prima é elaborada para a produção". Desse modo, prossegue Marx, a indústria extrativista não possibilita "nenhum processo de reprodução, pelo menos um processo que esteja sob nosso controle ou que seja do nosso conhecimento" ${ }^{6}$. Já n'O Capital, Marx afirma que na indústria extrativista, o objeto do trabalho não é "o produto de trabalho prévio, mas presenteado gratuitamente pela natureza. São os minérios metálicos, minerais, carvão de pedra, pedras, etc”. Nesse contexto, o capital constante consiste quase exclusivamente em meios de trabalho que podem suportar muito bem uma "ampliação do quantum de trabalho (...), porém, permanecendo constantes as demais circunstâncias, a massa e o valor do produto sobem em razão do trabalho empregado (...), aqui os formadores originais do produto, portanto também os formadores dos elementos materiais do capital, homem e Natureza vão juntos" 7 . Nesse sentido, o uso crescente dos combustíveis fósseis não pode ser compreendido se a eles estiverem desvinculadas as intenções e consequências do aumento do extrativismo propiciado pelo advento do modo de produção capitalista ${ }^{8}$. Ao deslocarmos a centralidade dessa questão para o foco que aqui propusemos, teremos indícios de que não foi o uso abusivo dos combustíveis fósseis que propiciou a existência do modo de produção capitalista; ao contrário, foram exatamente as necessidades do capitalismo que implicaram no uso abusivo dos combustíveis fósseis.

Todavia há um afã em aproximar o "nós”, sujeitos sociais, do "modo de produção" vigente, como se uma forma social fosse condicionada ao aceite e à sujeição dos indivíduos que nela se constituem socialmente; como se o desenvolvimento histórico não fosse condicionado à história precedente; como se os homens fizessem sua própria história de livre e espontânea vontade; como se eles escolhessem as circunstâncias sob as quais ela é feita; como se estas não lhe fossem transmitidas assim como se encontram?. Por esse motivo não nos faz sentido a passagem de Donna Haraway - citada e reiterada por Tible - em que ela afirma categoricamente que "culpar o Capitalismo, o Imperialismo, o Neoliberalismo, a Modernização, ou algum outro 'não nós' pela destruição em curso, pavimentada pelo aumento populacional (...) não vai funcionar”"

6 MARX, Karl. Grundrisse: manuscritos econômicos de I857-1858: esboços da crítica da economia política. São Paulo: Boitempo Editorial, 20II, 792 p.

7 MARX, Karl. O Capital: Crítica da economia política. Livro I: o processo de produção do capital. São Paulo: Boitempo editorial, 2013, 894 p.

8 Quanto à relação entre Marx e o capital extrativista, um belo artigo de autoria de Vitor Sartori chamado Marx, natureza e mineração, que está no prelo, é mais resolutivo nessas questões.

9 “Os homens fazem a sua própria história; contudo, não a fazem de livre e espontânea vontade, pois não são eles quem escolhem as circunstâncias sob as quais ela é feita, mas estas lhes foram transmitidas assim como se encontram” MARX, Karl. O I8 de Brumário de Luis Bonaparte. São Paulo: Boitempo editorial, 20II, p.25.

Io HARAWAY, Donna. Antropoceno, Capitaloceno, Plantatioceno, Chthuloceno: fazendo parentes. ClimaCom Cultura Cientifica - pesquisa, jornalismo e arte I Ano 3 - N. 5 / Abril de 2016. 
O chamado Antropoceno é, portanto, uma forma pela qual a esquerda não marxista - e mesmo parte que se reivindica como parte desta, como podemos aqui observar - tenta contornar o que é incontornável: o modo de produção capitalista e suas consequências deletérias. Um exercício eufêmico, diante dessa constatação, tem sido o uso do termo "capitaloceno"," conforme referendado por Tible, para caracterizar a atual forma geológica. Nos chamados Cadernos Etnológicos Marx já se opunha a essa "casuística inata do homem em querer mudar as coisas mudando de nome!" ". Segundo Marx, "o que diferencia as épocas econômicas não é 'o que' é produzido, mas 'como', 'com que meios de trabalho'” ${ }_{13}$ e assim, obviamente, não encontramos nas formas geológicas a resposta para compreendermos as especificidades das distintas formas sociais nem tampouco a resposta para a compreensão do tempo presente permeado sob o modo de produção capitalista. O que não significa que as mudanças geológicas não reproduzem as consequências destrutivas do capitalismo. Contudo, como meio de apreensão do real, essa não é uma esfera resolutiva. Portanto, nossa visão da realidade não pode ser compreendida meramente por meio de uma "visão objetiva", como sugere Tible baseado em Haraway, mas sim, por meio de uma visão da totalidade das categorias sociais que valorize também as especificidades locais.

2) Desloquemos para a segunda formulação de Tible, a qual se ampara na suposta constatação de que Marx e o marxismo não teriam levado a sério "o fato de as resistências e alternativas ao capitalismo sempre envolverem múltiplos sujeitos” baseado numa suposta primazia de Marx e do marxismo no sentido de conceber um único "sujeito revolucionário: trava-se do operário industrial (e principalmente homem, branco, europeu ocidental)". Antes de avançarmos nessa formulação, uma advertência: chega a ser aviltante a caracterização do operário como "homem, branco, europeu ocidental" na medida em que essas caracterizaçôes, mesmo nos círculos da literatura identitária contemporânea, destacam, ao contrário, não as classes desfavorecidas, mas antes, as classes dominantes. As extensas horas diárias de trabalho, as condições desfavoráveis da produção, a baixa remuneração, a propensão a diversos tipos de doenças, o alto índice de suicídio no interior da classe e as quase inexistentes horas diárias destinadas ao lazer ${ }^{14}$ não fornecem ao operariado, ou melhor, ao proletariado, como distingue Marx, alguma espécie de "privilégio” em ser considerado como um "sujeito revolucionário",

II Cf. MOORE, Jason (Org.). Anthropocene or Capitalocene? Nature, history and the Crisis of Capitalism. PM Press, 20I6, 240p.

I2 MARX, Karl. The Ethnological Notebooks. (Edition: Lawrence Krader). Assen: Van Gorcum \& Comp. I972, 454p.

I3 MARX, Karl. O Capital: Crítica da economia política. Livro I: o processo de produção do capital. São Paulo: Boitempo editorial, 2013, 894p.

I4 Quanto à situação do operariado inglês, conferir: ENGELS, Friedrich. A situação da classe trabalhadora na Inglaterra. São Paulo: Boitempo editorial, 2010, $383 \mathrm{p}$. 


\section{R E V I S T A A N G E L S N O V U S}

ao contrário, essa péssima condição de vida e sociabilidade encontraria numa revolução uma esperança àqueles que não têm nada a perder a não ser suas correntes. O que não significa que não existam outros "sujeitos” que são próprios da sociabilidade capitalista que estejam em situações ainda mais degradantes. Trata-se apenas de uma distinção de exercício de análise por meio da qual enunciaremos através de qual lente devemos enxergar esses sujeitos. Para tanto, novamente vamos recorrer a Marx para desvendarmos em que ele atesta para uma primazia do proletário enquanto sujeito revolucionário.

Marx não concebe “o sujeito revolucionário” como algo peremptório. É fundamental notarmos que a contradição essencial da sociedade que adota o modo de produção capitalista está assentada na oposição entre burguesia e operariado industrial, mas essa afirmativa não condiciona uma "fórmula" revolucionária por meio da qual em todas as revoluções sociais o proletário seria esse único "sujeito revolucionário". Como pode Marx e o marxismo terem concebido apenas o proletário como sujeito revolucionário se o próprio Tible atesta, em outros momentos do texto aqui resenhado, que Marx teria notado o “potencial comunista” da comuna rural russa assim como um "ímpeto libertário" dos povos iroqueses? É verdade que retomaremos mais adiante a discussão quanto a esses dois “sujeitos”, mas parece-nos que as posições de Marx frente a outras possibilidades revolucionárias contradizem a interpretação inicial de Tible - e, para sermos justos, poucos como Tible conhecem tão bem a literatura que atravessa essas perspectivas que permeiam os textos finais da vida de Marx.

É necessário dizer que, tendo em consideração a extensão da obra de Marx, não podemos conceber a existência de um único "sujeito revolucionário". Um exemplo concreto através de uma análise de realidade pode ser notado n' A guerra civil na França, circunstância em que Marx, mesmo tendo como referência o operário parisiense, se utiliza em grande medida do termo "classes trabalhadoras" com base nas especificidades locais para se referir aos sujeitos da revolução social. Ainda mais convincente é a posição de Marx no que se refere às contradições postas na guerra civil estadunidense, em que Marx atesta para a possibilidade de uma "revolução escrava" como a melhor cartada que poderia ser tirada da manga do Norte contra o Sul's. Ou seja, mediante as especificidades que constituíam a realidade da guerra civil estadunidense, o "sujeito revolucionário" naquelas circunstâncias era distinto daquele inglês situado no local de maior desenvolvimento da grande indústria até então.

I5 “(...) com o tempo, é claro, o Norte vencerá, pois em caso de necessidade, ele pode jogar a melhor carta, a da revolução escrava” [Marx apud: ANDERSON, Kevin. Marx nas Margens: nacionalismos, etnias e sociedades não ocidentais (Tradução: Allan Hillani e Pedro Davoglio). São Paulo: Boitempo Editorial, 20I9, p.I46]. 
Para finalizarmos esse tópico, Tible prossegue com a suposição de que Marx e o marxismo não levaram em conta alguns elos, como "capitalismo e patriarcado" e "capitalismo e racismo". É notória a intenção de Tible em não só submeter o estatuto teórico de Marx às discussões contemporâneas assim chamadas "identitárias" como também em circunscrever Marx a essa razão. Para avançarmos em nossa discussão e superar essa acusação que já foi confrontada por diversas produçóes no âmbito do marxismo - mesmo atestando em Marx uma preocupação diante dessas especificidades, assim como contribuindo a seu modo com tais temáticas - terminemos, portanto, com a hipótese central de Tible, a saber: a de que Marx muda o seu pensamento a partir de seu contato com o que o autor de Marx Selvagem chama de "lutas".

3) Por um lado existe algo um tanto quanto óbvio na afirmação de que Marx muda o seu pensamento. Evidentemente poderíamos partir de um pressuposto de que para o autor de O Capital o que principalmente importa é a compreensão das determinações da realidade. Como sabemos, a realidade não se conforma de um modo estático, mas ao contrário, a partir de seu movimento constante. Assim, a compreensão de Marx em relação a circunstâncias e especificidades distintas, jamais poderia se conformar de maneira estática. Se seguíssemos esse raciocínio, poderíamos inferir que o contato de Marx com as tais "lutas" mencionadas por Tible podem afetar o modo pelo qual o autor de $O$ Capital compreende, de maneira consequente, a realidade. Contudo, essa mudança não seria uma especificidade do "contato com as lutas", mas sim, do próprio contato com a realidade movente. Todavia não nos parece ser esse o fato que motiva Tible a propor sua interpretação desse autor. Tentemos, portanto, compreender sua linha de raciocínio.

Por "lutas", Tible remete a alguma espécie de acontecimento histórico insurgente ou revolucionário - bem como a circunstâncias nas quais os personagens envolvidos se apresentam em um contexto de uma suposta "resistência” a determinada ameaça. Por meio de alguns exemplos mencionados pelo autor isso fica bastante evidente: a citação dos anos "I848/1871" trata respectivamente de dois acontecimentos históricos que foram absolutamente importantes para o desenvolvimento teórico e prático de Marx - referimo-nos, é claro, à Primavera dos Povos e à Comuna de Paris. Quanto ao primeiro desses eventos, sabemos que naquele contexto Marx era membro das fileiras da Liga dos Comunistas, movimento em que foi designado, em parceria com Engels, a produzir um dos documentos mais importantes da tradição revolucionária: o conhecido Manifesto do Partido Comunista; já no que se refere à Comuna de Paris, a primeira experiência anticapitalista de tomada real do poder por parte da classe trabalhadora, tal episódio foi retratado por Marx em alguns textos 


\section{R E V I S T A A N G E L S N O V U S}

publicados posteriormente como A Guerra Civil na França. Assim, nos referimos a dois dos principais eventos do século XIX que foram contemporâneos a Marx.

A leitura de um livro inédito por parte de um estudante trará uma complementariedade para seu conhecimento que poderá, por consequência, fazer com que ele possa rever alguns de seus pressupostos. Assim também o é com a descoberta de um fóssil desconhecido por parte de um arqueólogo, fato que certamente o exigirá uma compreensão específica desse achado e sua inserção naquele contexto. Não seria diferente quando um investigador que se propõe a compreender a realidade efetiva se defronta com um importante acontecimento histórico que é constitutivo do movimento dessa própria realidade. A mudança do pensamento de Marx a partir de seu contato com um evento histórico não é um exercício de contingência, mas antes, uma consequência imediata de sua posição frente a sua compreensão da realidade.

A crítica a essa formulação de Tible - a saber, que as mudanças no pensamento de Marx coincidem com seu contato com as "lutas" - é um tanto quanto delicada pois pode parecer que nossa intenção aqui seria a de deslegitimar determinada atuação de algumas formas de organização. Entretanto, adiantaremos nosso raciocínio para depois o justificarmos: as "comunas rurais da Rússia”, bem como a "organização iroquesa” - elencadas por Tible como resistências - não se apresentam em Marx como um "luta” nos moldes propostos por Tible. Entendam-nos bem: não queremos defender que tais experiências são inertes ou mesmo inofensivas, por assim dizer, nem mesmo queremos inferir uma não potencialidade revolucionária das mesmas. Se compreendermos, por exemplo, as especificidades das comunas rurais russas na segunda metade do século XIX, notaremos que foi exatamente nessa forma social que Marx apostou suas fichas para uma revolução social naquele país. Entretanto, se tivermos como exemplo a leitura de Marx da obra Ancient Society, obra na qual Morgan retrata, dentre outras informações, as especificidades de organização iroquesa, concluiremos que Marx não teve contato com a "luta iroquesa", mas sim, com a "sociedade iroquesa" conforme descrita por Morgan.

Uma interpretação precipitada seria dizer que tal sociedade, ao se encontrar em uma circunstância de resistência ao modo de produção capitalista poderia ser concebida como uma situação de "luta". Entretanto, a leitura de um autor como Morgan, que Marx trata como "um burguês americano nem um pouco suspeito de tendências revolucionárias" ${ }^{16}$ não nos remete a mais do que o conhecimento de Marx das informaçóes contidas na obra Ancient Society, que apresenta, a saber, uma comparação entre o que o antropólogo chama de “comunidades gentílicas” romana, grega e iroquesa. Vale ressaltar, inclusive, que Ancient 
Society sequer é uma obra específica sobre a organização iroquesa; a esse propósito Morgan publicou, em I851, a obra League of Iroquois ${ }^{17}$. Além disso, até que nos provem ao contrário, podemos afirmar que não há nenhuma evidência no tratamento de Morgan da sociedade iroquesa que conduza a tal leitura, a saber, que os iroqueses estão "resistindo" a algo e, claro, em momento algum Marx evidencia isso em seus Cadernos Etnológicos. Isso não significa que esses povos não "resistam" nos moldes propostos por Tible. Apenas chamamos a atenção para o fato de que esse foco nunca foi o interesse de Lewis Morgan em Ancient Society.

O inusitado é que Lévi-Strauss, em um subcapítulo de Antropologia Estrutural Dois, vai tratar da resistência de algumas formas de sociabilidade ao desenvolvimento capitalista. Todavia, antes de avançar na exposição, o autor francês demonstra a necessidade de distinguir alguns casos excepcionais em que determinadas culturas indígenas tradicionais conseguem se adaptar a esse modo de produção. A esse propósito, Lévi-Strauss menciona exatamente os "Iroqueses do estado de Nova York, que há mais de meio século fornecem as melhores equipes especializadas na montagem de estruturas metálicas como pontes, arranha-céus etc”. O estruturalista sugere que "talvez esses índios tenham encontrado nessa atividade arriscada, geradora de prestígio e muito bem remunerada - e também intermitente, o que implica certo nomadismo - um substituto para suas antigas expedições de guerra" ${ }^{18}$. O tratamento de Tible aos índios Iroqueses na leitura de Marx à obra de Morgan como uma "luta" se aproxima do que Alcida Rita Ramos discute a partir da abordagem do ativismo indigenista junto das povos ameríndios remetendo à noção de um "índio hiper-real”, ou seja, com “princípios virtuosos, pureza ideológica, disposição de morrer heroicamente e outras proezas morais que não são mais do que fantasias de branco" ". Portanto, a hipótese central de Tible, apesar de se basear no pensamento de Marx, não possui, em nossa interpretação, uma base real no estatuto teórico de Marx que a sustente.

$\mathrm{Na}$ última ocasião em que tratamos criticamente de um texto do Tible, sugerimos que "ao passo em que Tible é adepto, Marx é crítico a uma espécie de 'razão etnológica”".

I7 Apenas o prefácio dessa obra foi traduzido para o português. Cf. MORGAN, Lewis. Prefácio à Liga dos Iroqueses (Tradução: Lucas Parreira Álvares) In: MIMEO: Boletim de traduções e documentos de Antropologia e áreas afins. Piauí: N.I., 2019, p.42-46.

I8 LÉVI-STRAUSS, Claude. Antropologia Estrutural Dois (Tradução: Beatriz Perrone-Moisés). São Paulo: Cosac Naify, 20I3, p.35I.

I9 RAMOS, Alcida Rita. O índio hiper-real. Revista Brasileira de Ciências Sociais. São Paulo, v. 28, n. Io, p. 5I4, 1995 . 


\section{R E VISTA A N G E L U N O V U S}

Contrapondo as distinções entre "etnologia" e "antropologia", desenvolvemos posteriormente um trabalho com a intenção de fornecer subsídios a essa nossa afirmação, tentando identificar o que chamamos de "razão antropológica" ${ }^{\circ}$. Com a produção dessa presente resenha crítica novas questões foram postas e novas possibilidades de desenvolvimentos teóricos foram manifestas. Nesse sentido, diante das inquietações presentes na constituição desse texto, levantamos uma nova hipótese a ser aprimorada em outra ocasião: Jean Tible, apesar de sua sagacidade em alguns momentos de suas exposiçóes, acredita estar desvinculando Marx de certa "domesticação" desenvolvida em seu nome, mas, como consequência, o autor de Marx Selvagem acaba domesticando Marx no interior de outras razões teóricas, como a própria razão antropológica e, conforme apresentado nesse texto, a razão identitária. Mas isso é assunto para ser discutido em outro momento. Por ora, vale apenas recordar que a crítica escolhe um alvo, mas na essência da crítica estão as formulações de quem a executa.

Recebido: 27/09/2019 Aceito: 31/10/2019 